
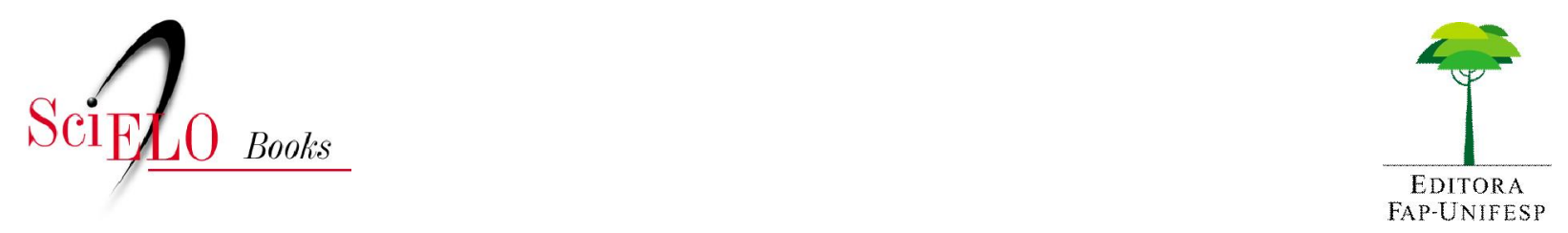

\title{
32 - A descoberta dos raios-X e o seu lado pitoresco
}

\author{
Joffre Marcondes de Rezende
}

REZENDE, JM. À sombra do plátano: crônicas de história da medicina [online]. São Paulo: Editora Unifesp, 2009. A descoberta dos raios-X e o seu lado pitoresco. pp. 265-268. ISBN 978-85-61673-63-

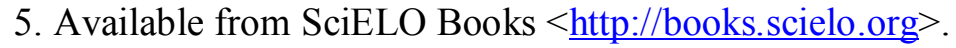

\section{(1) (1) $\Theta(9)$}

All the contents of this work, except where otherwise noted, is licensed under a Creative Commons Attribution-Non Commercial-ShareAlike 3.0 Unported.

Todo o conteúdo deste trabalho, exceto quando houver ressalva, é publicado sob a licença Creative Commons Atribuição Uso Não Comercial - Partilha nos Mesmos Termos 3.0 Não adaptada.

Todo el contenido de esta obra, excepto donde se indique lo contrario, está bajo licencia de la licencia Creative Commons Reconocimento-NoComercial-CompartirIgual 3.0 Unported. 


\section{2}

\section{A Descoberta dos Raios-X e o seu Lado Pitoresco}

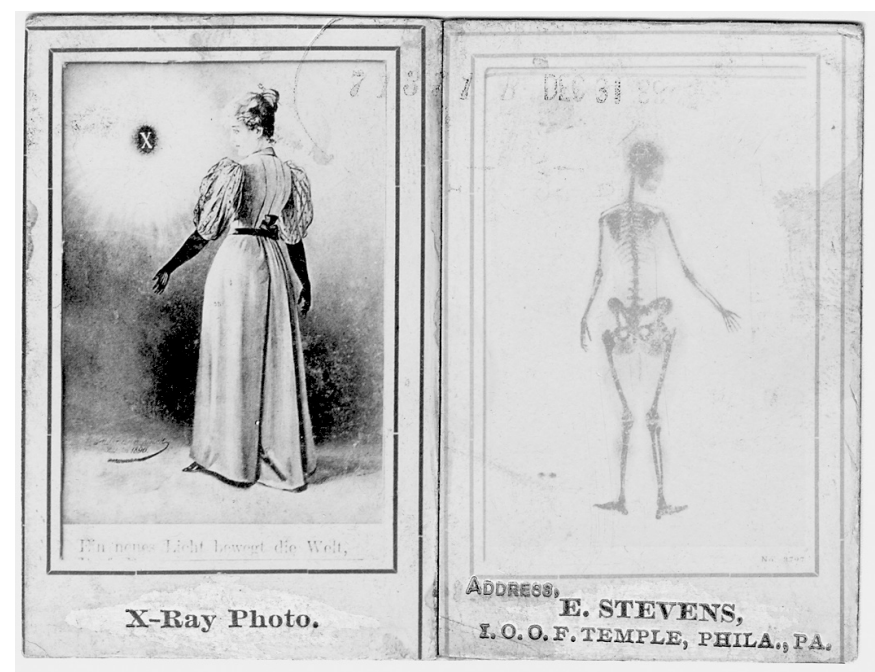

Representação de uma mulher com o uso dos raios-X, I 896 .

$\mathrm{A}_{\text {impacto não somente nos meios científicos, mas também entre os leigos. }}$ Sabia-se que algo de extraordinário fora descoberto e previa-se uma nova era para a medicina. O que mais impressionava as pessoas era o poder de penetração dos raios-X e a possibilidade de visualização do interior do corpo humano através das vestes e do tegumento cutâneo. A imagem obtida com os raios catódicos foi de início considerada como um tipo especial de fotografia.

A simplicidade dos primeiros aparelhos fez com que surgissem muitos amadores com instalações improvisadas, oferecendo fotografias com os misteriosos raios-X. Era comum, entre namorados, a troca de fotografias das mãos feitas com os raios-X.

Lojas de material fotográfico ofereciam componentes para a montagem de um aparelho simples de raios-X que permitia reproduzir as experiências de Roentgen (Reiser, I978, pp. 60-62).

A imprensa de vários países noticiou a descoberta com grande destaque e houve diversas manifestações, partidas dos mais diferentes setores da so- 


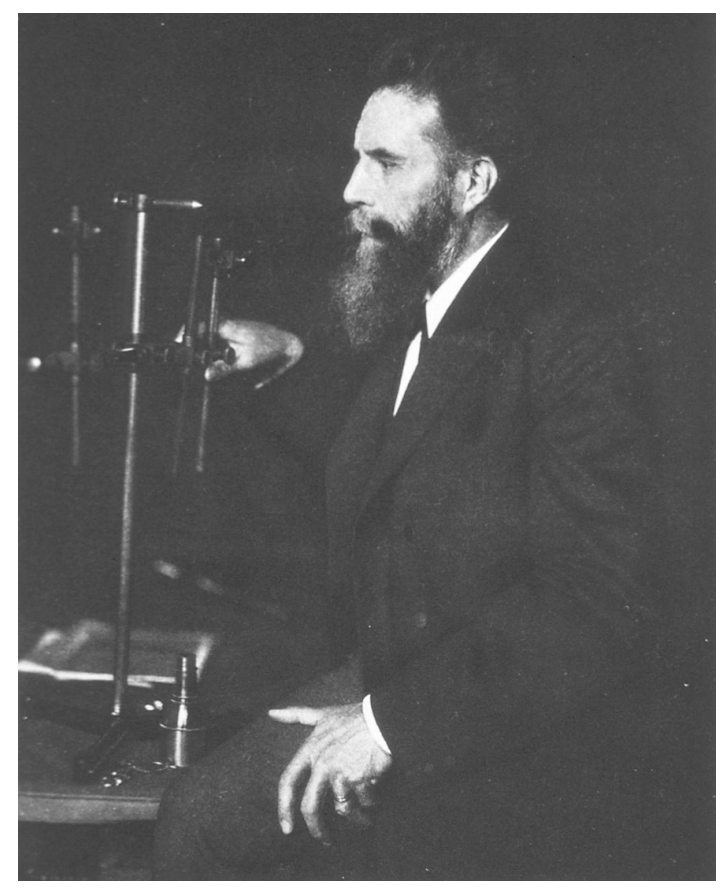

Wilhelm Konrad Roentgen, descobridor dos raios-X.

ciedade. A maioria de tais manifestações, veiculadas pela imprensa, era de admiração e louvor ao notável feito do físico alemão; algumas, entretanto, caracterizavam-se pelo lado ridículo ou pelo senso de humor.

Conforme relata Alan Bleich em seu livro The story of X-rays from Roentgen to Isotopes, de I960, a radiografia passou a ser objeto de curiosidade e até de preocupação, pois invadia a privacidade do corpo humano, oferecendo do mesmo uma representação fotográfica inestética (Bleich, I960, pp. 3-7).

Uma loja de confecções de Londres chegou a anunciar a venda de roupas íntimas à prova de raios-X.

Um deputado, em New Jersey, nos Estados Unidos, apresentou um projeto de lei proibindo o uso, no teatro, de binóculo provido de raios-X.

Em New York a fluoroscopia era anunciada como "espetáculos de Roentgen”, ao preço de cinco a vinte dólares.

A revista Life, em fevereiro de I 896, publicou a seguinte poesia, de autoria de Lawrence K. Russel, que apresentamos em tradução livre: 
Ela é tão alta, tão esbelta; e seus ossos, aqueles débeis fosfatos e aqueles carbonatos tornam-se magníficos aos raios catódicos pelas oscilações, amperes e ohms; suas vértebras não se ocultam sob a pele, mas tornam-se inteiramente visíveis.

Em torno de suas formosas costelas em número de vinte e quatro desenha-se um tênue halo de sua carne; sua face sem nariz e sem olhos volta-se para mim e eu sussurro: "querida eu te adoro"; seus dentes brancos e brilhantes sorriem.

Ah! doce, cruel, adorável catodografia.

A revista Photography, na mesma época, contribuiu com esta outra poesia, que também apresentamos em tradução livre:

Os raios Roentgen, os raios Roentgen, que viraram mania e excitam a cidade com a nova fase de rumos futuros, me deixam aturdido, pois agora eu percebo que se pode ver e mirar através dos vestidos com estes travessos raios, malvados raios Roentgen.

Somente depois que se tornaram conhecidos os efeitos nocivos dos raios-X sobre o organismo humano é que o seu uso se restringiu aos hospitais e clínicas especializadas, inicialmente para fins diagnósticos e, posteriormente, também para fins terapêuticos no tratamento de neoplasias malignas. 
Ainda assim, as primitivas instalações não ofereciam proteção adequada e muitos médicos e operadores de aparelhos de raios-X foram vítimas das radiações, apresentando radiodermite nas mãos, que poderiam levar à amputação, e alta incidência de leucemia.

\section{Referências Bibliográficas}

BleIch, A. The Story of X-rays from Roentgen to Isotopes. New York, Dover Publications, 1960.

Reiser, S. J. Medicine and the Reign of Technology. Cambridge, Cambridge University Press, 1978. 